\title{
Modeling Relative Contact Bearing Area of Titanium Parts during Grinding
}

\author{
Soler Yakov Iosifovich \\ Technology and Equipment of Mechanical Manufacture \\ Department \\ Irkutsk National Research Technical University \\ Irkutsk, Russia \\ solera@istu.irk.ru
}

Nguyen Van Le

Technology and Equipment of Mechanical Manufacture Department

Irkutsk National Research Technical University Irkutsk, Russia

\author{
Mai Dinh Si \\ Technology and Equipment of Mechanical Manufacture \\ Department \\ Irkutsk National Research Technical University \\ Irkutsk, Russia \\ mdsmm07@gmail.com
}

\author{
Kazimirov Denis Yurievich \\ Technology and Equipment of Mechanical Manufacture \\ Department \\ Irkutsk National Research Technical University \\ Irkutsk, Russia
}

\begin{abstract}
The models of multivariate analysis of variance and models of artificial neural networks based on the D-optimal design of experiment were carried out to predict the relative contact bearing area $\left(t_{f M}, \%\right)$ of the parts from titanium alloy VT22 during grinding. Parameter $t_{f M}$ of part surface, measured using digital technologies, was sensitive to the variation of the technological parameters of the grinding mode. As a result of the analysis, the decrease of technological parameters is not always accompanied by the increase of the predicted value of the relative contact bearing area. In this case, with the aim of increasing the process productivity and the relative contact bearing area of ground surfaces, the parts from titanium alloy VT22 are recommended to grind by the following modes: for rough stage $s_{l}=5-12 \mathrm{~m} / \mathrm{min}, s_{c r}=9-10 \mathrm{~mm} /$ double stroke, $t=0.02 \mathrm{~mm}, z=0.3$ $\mathrm{mm}$; and for finishing stage $-s_{l}=18 \mathrm{~m} / \mathrm{min}, s_{c r}=4 \mathrm{~mm} /$ double stroke, $t=0.006 \mathrm{~mm}, z=0.1 \mathrm{~mm}$.
\end{abstract}

Keywords-artificial neural network; grinding; modeling; relative contact bearing area; titanium alloy

\section{INTRODUCTION}

A real surface geometry of any part significantly differs from an ideal one. The surface trimming of solids is always discrete, i.e. there is the place on separate area. This is due to the fact that after any processing method, macro- and microgeometry are present on the real part surface, which has a different amount. It has significant effect on the operating ability of machine parts and their joints: wearing capacity, contact rigidity, corrosion stability, fatigue resistance, tightness etc. [1-4].

To obtain information about the shape and characteristics of the contact surfaces, various methods are used: adhesion, geometric, electrical, etc. The paper [5] was devoted to the adhesion method for determining the actual contact area using thin carbon films, which were marked on one of trimming surfaces in a vacuum. In this case, an actual contact area is determined by the area of destruction of these films at the points of contact. However, this method requires special equipment, which makes it difficult to widely use it in practice. In [6] two methods for determining an actual contact area were presented. The first method is realized by feed of gas (or liquid) under pressure into contactless areas. In this case, there is a pressure force of the gas (or liquid) on the surface areas where there is no contact. The value of this force allows to estimate the area of the contactless region. According to the second method, a dye is introduced into the allowances between the contact surfaces. It is deposited on free areas between the trimming surfaces. After disassembly, the actual contact areas remain unpainted. They are summed up using a microscope or a calibrated photometer. These methods are not suitable for comparing the scale-variable details presented with different magnifications. Attention is drawn to the electric method for determining the contact bearing area for electrically conductive products [7]. Taking into account the part material and the calibrated instrument, the resistance is determined and the bearing area of surface irregularities is estimated.

We have developed a new method for diagnosing surface contact called digital topography, which allows to take into account the nature of the topometric structure of surfaces [8]. The relative bearing area is determined by this method by means of revealing the zones of probable contact of the part base surfaces. It is quite simple and allows to shorten the experiment time with sufficiently high accuracy without using special expensive devices. A working surface of the machine parts is mainly formed at their final processing stage, which is usually grinding process for the responsible parts [9]. The problems, which are arisen while grinding the parts from titanium alloys, have not been adequately studied yet. These parts have low grindability [10-15] because of adhesion and diffusion interaction between abrasive grains and titanium alloys. To reduce these defects high porous wheels made from 
CBN [1,13-15] are used. They provide increasing grinding efficiency of titanium parts up to 8-10 times. The large pores of these wheels allow to take places into them the chips. They reduce the blunting of the wheel and also improve feeding conditions of the coolant to cutting zone, which prevents the occurrence of grinding burns and surface cracks.

At present time, the following different methods: finite element modeling, artificial neural network (ANN) method, fuzzy logic and multiple regression analysis [16-20] are widely used. At that application of ANN is the most perspective to diagnose grinding process. ANN are a powerful tool, especially when the relationship between the analyzed is unknown. Until now, there are not much works, which were successfully used ANN to solve various problems in grinding process. In [17] ANN was used for modeling and predicting the roughness parameters of the ground surfaces during cylindrical grinding of parts from the metal matrix composite $\mathrm{SiCp}$. Another approach, which we are interested to search for models, is regression analysis using least squares method and maximum-likelihood method. In [20] statistical models were constructed to predict the grinding burns of processing surface. These models allow to control grinding process taking into account the grinding productivity in a limited factor space.

Based on the aforesaid, the aim of this study is to model and predict the relative contact bearing area of the parts from titanium alloy VT22 using ANN while grinding by CBN wheels. After that, a comparison of received results of output parameter of the ANN models and the models of multivariate analysis of variance (MANOVA) is carried out.

\section{METHODS}

\section{A. Experimental Technique}

Grinding process was carried out under the following constant conditions: flat-surface grinding machine $3 \mathrm{E} 711 \mathrm{~V}$; high porous wheel made from $\mathrm{CBN}$ with $1 \mathrm{~A} 1$ form and dimensions of $200 \times 20 \times 76 \times 5 \mathrm{~mm} \mathrm{CBN30} \mathrm{B107} 100 \mathrm{OV}$ K27 KF40 according to the GOST 53922-2010, GOST 539232010; cutting speed $v_{w}=28 \mathrm{~m} / \mathrm{s}$; lubricoolant $5 \%$ Akvol-6 emulsion (TY 0258-024-00148845-98) was supplied flowing on the workpiece in the amount of $7-10 \mathrm{l} / \mathrm{min}$; investigation subject is flat workpieces made of titanium alloy VT22 with the following mechanical properties: $\sigma_{\text {strength limit }}=1400 \mathrm{MPa}$; relative extension $\delta=8 \%$ and dimensions of $B \times L \times H=40 \times 40 \times 40 \mathrm{~mm}$, ground butt end $B \times L$. Variable technological parameters are given in Table 1.
TABLE I. VARIATION INTERVALS AND LEVELS OF NATURAL AND NORMALIZED FACTORS

\begin{tabular}{|l|c|c|c|c|}
\hline \multicolumn{1}{|c|}{ Factor } & $\begin{array}{c}\text { Variation } \\
\text { interval }\end{array}$ & \multicolumn{3}{|c|}{ Factor level } \\
\hline & & $\begin{array}{c}\text { lower } \\
(-1)\end{array}$ & $\begin{array}{c}\text { base } \\
(\boldsymbol{0})\end{array}$ & $\begin{array}{c}\text { upper } \\
(+1)\end{array}$ \\
\hline$A-$ longitudinal feed $s_{l}(\mathrm{~m} / \mathrm{min})$ & 6.5 & 5.0 & 11.5 & 18.0 \\
\hline $\begin{array}{l}B-\text { cross feed } s_{c r}(\mathrm{~mm} / \text { double } \\
\text { stroke) }\end{array}$ & 4 & 2 & 6 & 10 \\
\hline$C-$ cutting depth $t(\mathrm{~mm})$ & 0.0075 & 0.005 & 0.0125 & 0.020 \\
\hline $\begin{array}{l}D-\text { operational allowance } z \\
(\mathrm{~mm})\end{array}$ & 0.1 & 0.1 & 0.2 & 0.3 \\
\hline
\end{tabular}

Variation of the factors is carried out by the $D$-optimal design of experiment with a test number of $N=38$ and their duplication of $n=3$ for each points of the plan (Table 2). Application of the criterion of the $D$-optimal design of experiment implies minimizing the determinant of the dispersion matrix, which in practice reduces the error magnitude while determining the regression coefficients and according to increase the accuracy of the predicted responses [21].

TABLE II. MATRIX OF D-OPTIMAL DESIGN OF EXPERIMENT

\begin{tabular}{|c|c|c|c|c|c|c|c|c|c|}
\hline \multirow[t]{2}{*}{ Number } & \multicolumn{4}{|c|}{$\begin{array}{c}\text { Normalization } \\
\text { factor levels }\end{array}$} & \multirow[t]{2}{*}{ Number } & \multicolumn{4}{|c|}{$\begin{array}{c}\text { Normalization factor } \\
\text { levels }\end{array}$} \\
\hline & $A$ & B & $C$ & $D$ & & $\boldsymbol{A}$ & $B$ & $C$ & $D$ \\
\hline 1 & 0 & -1 & -1 & -1 & 20 & -1 & 1 & 0 & 0 \\
\hline 2 & -1 & 0 & -1 & -1 & 21 & -1 & -1 & 1 & 0 \\
\hline 3 & 0 & 1 & -1 & -1 & 22 & 0 & -1 & 1 & 0 \\
\hline 4 & 1 & 1 & -1 & -1 & 23 & -1 & 0 & 1 & 0 \\
\hline 5 & -1 & -1 & 0 & -1 & 24 & 1 & 0 & 1 & 0 \\
\hline 6 & 1 & -1 & 0 & -1 & 25 & 0 & 1 & 1 & 0 \\
\hline 7 & 0 & 0 & 0 & -1 & 26 & 1 & 1 & 1 & 0 \\
\hline 8 & 0 & 1 & 0 & -1 & 27 & 0 & -1 & -1 & 1 \\
\hline 9 & 0 & -1 & 1 & -1 & 28 & 0 & 0 & -1 & 1 \\
\hline 10 & 0 & 0 & 1 & -1 & 29 & 1 & 0 & -1 & 1 \\
\hline 11 & 1 & 0 & 1 & -1 & 30 & -1 & 1 & -1 & 1 \\
\hline 12 & -1 & 1 & 1 & -1 & 31 & 0 & -1 & 0 & 1 \\
\hline 13 & -1 & -1 & -1 & 0 & 32 & -1 & 0 & 0 & 1 \\
\hline 14 & 1 & -1 & -1 & 0 & 33 & 0 & 1 & 0 & 1 \\
\hline 15 & 0 & 0 & -1 & 0 & 34 & 1 & 1 & 0 & 1 \\
\hline 16 & 0 & 1 & -1 & 0 & 35 & -1 & -1 & 1 & 1 \\
\hline 17 & 0 & -1 & 0 & 0 & 36 & -1 & -1 & 1 & 1 \\
\hline 18 & 0 & 0 & 0 & 0 & 37 & 0 & 0 & 1 & 1 \\
\hline 19 & 1 & 0 & 0 & 0 & 38 & 0 & 1 & 1 & 1 \\
\hline
\end{tabular}

\section{B. Method for measuring the relative contact bearing area}

The relative contact bearing area of the ground surfaces was measured by the method presented in papers [8]. In this case, a new parameter has been suggested for numerical description of a carrier plane: 


$$
t_{f M}=\left(1-\frac{F_{d}}{F_{\Sigma}}\right) \times 100(\%),
$$

where $f M$ is an index that gives the depth of a depression, which corresponds to the thickness of the filler indicator; $F_{\Sigma}$, total area of projection; and $F_{d}$, area of projection of depression.

The pictures of ground surfaces, obtained after shooting under certain conditions, are converted into a 16-bit color pictures (Fig. 1). The equation (1) is converted taking into account the pixel frequency by the following equation:

$$
t_{f M}=\left(1-\sum P_{r e d} / \sum P_{k}\right) \times 100(\%)
$$

where $\Sigma P_{k}$ and $\Sigma P_{\text {red }}$ are the number of pixels correspondingly of all the colors (with $k \leq 16$ ) and of the red spectrum.
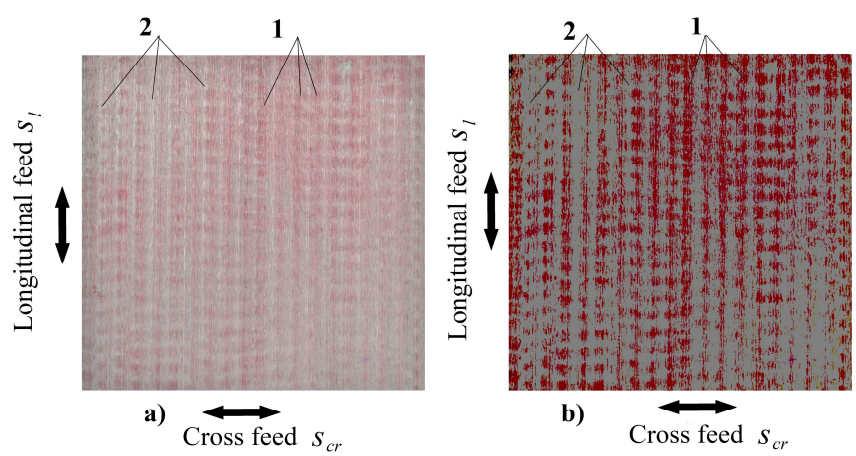

Fig. 1. Images of ground surface in the mode: $s_{l}=5(\mathrm{~m} / \mathrm{min}), s_{c r}=2$ $\mathrm{mm} /$ double stroke, $t=0.0125 \mathrm{~mm}, z=0.1 \mathrm{~mm}: \mathrm{a}$ - original picture; $\mathrm{b}-$ the picture converted into a 16-bit color one (1 - depression areas; 2 - contact areas)

By the analysis result presented in Fig. 1 and in Table 3 the relative contact bearing area of this surface is amounted to $t_{f M}$ $=68.54 \%$ (2).

TABLE III. PIXEL FREQUENCY DISTRIBUTION OF EACH COLOR WHILE GRINDING ONE PART IN THE FIG. 1

\begin{tabular}{|c|c|c|c|}
\hline $\begin{array}{c}\text { Color. } \\
\boldsymbol{k}=\overline{\mathbf{1 ;} 7} \cdot\end{array}$ & $\begin{array}{c}\text { Pixel number } \\
\text { (pixel) }\end{array}$ & $\boldsymbol{R G B \text { -code }}$ & HTML-code \\
\hline 1 & 9878 & $(0,0,0)$ & $\# 000000$ black \\
\hline 2 & 7 & $(0,0,128)$ & $\# 000080$ navy \\
\hline 3 & 637 & $(0,128,0)$ & $\# 008000$ green \\
\hline $\mathbf{4}$ & $\mathbf{1 6 7 8 4 9 8}$ & $\mathbf{( 1 2 8 , 0 , 0 )}$ & $\# \mathbf{8 0 0 0 0 0}$ maroon \\
\hline $\mathbf{5}$ & $\mathbf{1 6 2 9 3 1}$ & $\mathbf{( 1 2 8 , 0 , 1 2 8 )}$ & \#800080 purple \\
\hline $\mathbf{6}$ & $\mathbf{1 7 0 0 1 6}$ & $\mathbf{( 1 2 8 , 1 2 8 , 0 )}$ & \#808000 olive \\
\hline 7 & 4371213 & $(128,128,128)$ & $\# 808080$ fractal \\
\hline
\end{tabular}

C. Method of modeling relative contact bearing area using ANN

There are different ANN: multilayer perceptrons; radial basis functions; self-organizing feature maps (Kohonen networks), etc. In this study, a multilayer perceptron ANN was used, which is simply interpreted as an input-output model.

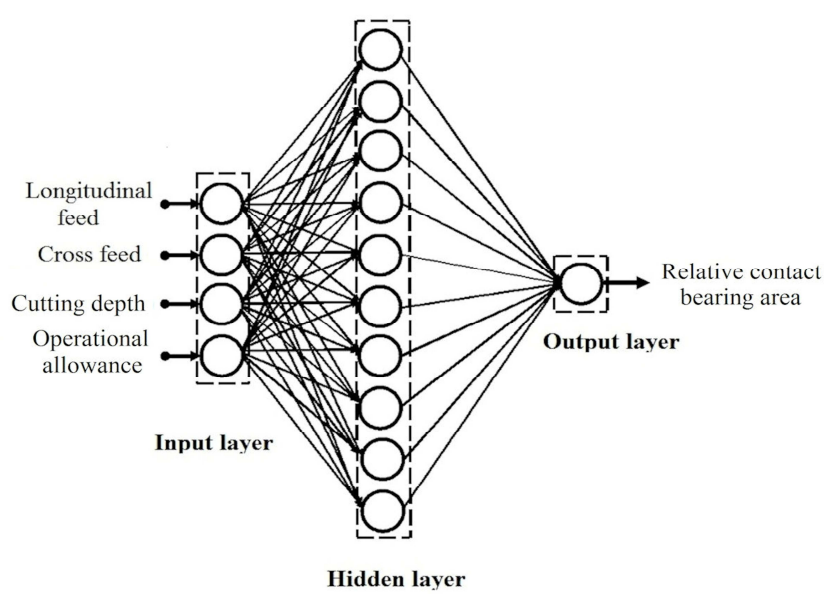

Fig. 2. Architecture of a multilayer ANN

The structure of multilayer ANN is shown in Fig. 2. The ANN architecture defines its structure, including input, output (neurons) and a set of hidden layers, in which there are the hidden neurons. This network can simulate a function of almost any degree of complexity. The number of input and output elements is determined by the problem conditions.

The selection of neuron number in the hidden layer plays an important role in determining the optimal model architecture. A network with fewer neurons may incorrectly reflect the input-output relationship, which increases prediction error. Their magnification improves network flexibility and the training effectiveness. However, a large neurons number in hidden layer can lead to an increase in network training time. The network retraining is manifested in the fact that the network on training access will work with very high accuracy, which decreases on the operating mode.

An artificial neuron is a system of two elements: an accumulator and a converter. It receives input signals, which are the original data or from the other neurons of previous ANN layer, through several input channels. The weighted sum of the inputs is calculated, as a result, the activation value of the neuron is obtained. After that, this value is converted using an activation function (or transfer function) for receiving the output signal of the neuron. The activation function $\mathrm{f}$ is intended to determine the output neuron value from the result of the accumulator (weighted sum of inputs).

TABLE IV.

ACTIVATION FUNCTIONS OF NEURONS

\begin{tabular}{|c|cc|c|}
\hline Type $\boldsymbol{f}$ & Formula & Field of application \\
\hline Identity & $y=a$ & $(3)$ & $(-\infty,+\infty)$ \\
\hline Logistic & $y=\frac{1}{1-e^{-a}} \quad(4)$ & $(0,+1)$ \\
\hline Hyperbolic & $y=\frac{e^{a}-e^{-a}}{e^{a}+e^{-a}} \quad(5)$ & $(-1,+1)$ \\
\hline Indicative & $y=e^{-a}$ & $(6)$ & $(0,+\infty)$ \\
\hline Sine & $y=\sin \alpha$ & $(7)$ & {$[0,+1]$} \\
\hline \multicolumn{2}{|c|}{ Note. a - input weight to a given neuron. } \\
\hline
\end{tabular}


For a multilayer perceptron, selection of the activation function type plays a very important role, because it can significantly influence the performance and accuracy of the network. There are different activation functions for multilayer perceptron to search for regression (Table 4). In the program, the hyperbolic function (5) is recommended to use for the neurons on hidden layers due to its symmetry property. On the output layer, the identity function (3) is usually used.

To build an ANN model, input parameters and purpose are specified. They are used as input data for training, monitoring and testing of the neural networks. In this case, $70 \%$ of the presented experiments were accidentally used for training, 15 $\%$ - respectively for their control and testing. ANN training was conducted with a change in the number of hidden layer neurons from 5 to 20 .

As a result of the neuron network modeling, ANN models with different structures were obtained. The model with the maximum performance and minimum error on all three subsets: training, control and test is chosen to predict the relative contact bearing area. The network performance refers to the ration of the standard deviation of network errors to the standard deviation of the original data.

\section{Method of constructing statistical models}

The statistical model of the studied parameter was constructed by the method presented in paper [20]. State-Ease Design-Expert 8.0.5 software was used to reduce timeconsuming and deepening representation about the phenomena studied. It has a set of tools for searching and analyzing the regression model.

\section{RESEARCH RESULTS AND DISCUSSION}

\section{A. Searching for the regression models}

The quadratic models were recommended by the StateEase Design-Expert 8.0.5 software. The significant main effects and their interactions at the $5 \%$ level have been chosen using the least squares method. The regression models of the relative contact bearing area were presented below:

- the normalized form

$$
\begin{gathered}
\hat{t}_{f M}=49.23-4.58 A-7.52 B-6.92 C-1.77 D-0.44 A C+ \\
+4.42 B D-4.42 C D-4.53 D^{2}(\%)
\end{gathered}
$$

- the nature form

$$
\begin{gathered}
\hat{t}_{f M}=51.005+0.433 s_{l}-4.089 s_{c r}+1302.364 t+170.982 z- \\
91.079 s_{1} t+11.041 s_{c r} z-5887.203 t z-453.391 z^{2}(\%) .(9)
\end{gathered}
$$

The obtained model (8) in the normalized form allows one to determine the effect of the technological factors on the variation of the predicted response by their sign and magnitude. So the cross feed is the most affected factor on the relative contact bearing area. The cutting depth is located behind it. Their growth, which is necessary to exceed the productivity of the grinding process, is accompanied by a negative decrease of the relative contact bearing area and the quality of the obtained parts. The pair interactions can enhance or weaken the manifestation of the main effects, depending on the sign of the coefficient.

\section{B. Selection and analysis of the ANN model}

For training ANN, the technological parameters were used as input signals: $s_{l}, s_{c r}, t, z$ (Table 2 ), and the relative contact bearing area $t_{f M}, \%(2)-$ the output signal. The network is trained using different activation functions (3) - (7) on the hidden and output layers. After the training process, ANN models were obtained with different structures. In this case a model, architecture of which is shown in Fig. 2, was chosen. It consists of: an input layer with four neurons, each of which is one variable input; a hidden layer (10 neurons) and an output layer with one neuron. It should be noted that in the selected model, the logistic function (4) is used to convert information on the hidden layer, and the identity function (3) - on the output layer.

Table 5 shows the results of experimental and predicted average values of the ANN model and the MANOVA model of 12 random points of $D$-optimal design of experiment. It is obvious that the ANN model provides a higher accuracy of predicting responses. The errors of the ANN model are varied from 0.008 to $19.37 \%$, and the average error amounted to $5.39 \%$. The maximum error of the MANOVA model increased to $28.22 \%$, and the average error - to $10.13 \%$. It has been established that the error of the ANN model is less almost two times than the error of the MANOVA model.

TABLE V. RESULTS OF EXPERIMENTAL AND PREDICTED AVERAGE VALUES OF THE ANN MODELS AND THE MANOVA MODELS

\begin{tabular}{|c|c|c|c|c|c|c|c|c|}
\hline \multicolumn{4}{|c|}{ Factor } & Experimental & \multicolumn{2}{c|}{ ANN model } & \multicolumn{2}{|c|}{ MANOVA model } \\
\hline $\boldsymbol{A}$ & $\boldsymbol{B}$ & $\boldsymbol{C}$ & $\boldsymbol{D}$ & $\begin{array}{c}\text { Predicted } \\
\text { average } \\
\boldsymbol{t}_{f M}(\boldsymbol{\%})\end{array}$ & $\begin{array}{c}\text { Pverage } \\
\hat{t}_{f M}(\boldsymbol{\%})\end{array}$ & $\begin{array}{c}\text { Error } \\
(\boldsymbol{\%})\end{array}$ & $\begin{array}{c}\text { Predicted } \\
\text { average } \\
\hat{t}_{f M}(\boldsymbol{\%})\end{array}$ & $\begin{array}{c}\text { Error } \\
(\boldsymbol{\%})\end{array}$ \\
\hline 0 & -1 & -1 & -1 & 60.95 & 59.17 & 2.92 & 60.91 & 0.07 \\
\hline-1 & 0 & -1 & -1 & 44.86 & 49.31 & 9.91 & 49.11 & 9.48 \\
\hline 0 & 1 & -1 & -1 & 46.96 & 44.08 & 6.14 & 37.03 & 21.19 \\
\hline 1 & 1 & -1 & -1 & 30.28 & 34.62 & 14.34 & 36.89 & 21.84 \\
\hline-1 & -1 & 0 & -1 & 64.29 & 64.02 & 0.42 & 62.99 & 2.02 \\
\hline 1 & -1 & 0 & -1 & 52.74 & 53.02 & 0.54 & 53.83 & 2.07 \\
\hline 1 & 0 & 1 & 0 & 37.91 & 33.51 & 11.60 & 33.29 & 12.18 \\
\hline 0 & 1 & 1 & 0 & 37.21 & 38.41 & 3.23 & 34.79 & 6.51 \\
\hline 1 & 1 & 1 & 0 & 28.27 & 29.80 & 5.39 & 25.77 & 8.84 \\
\hline 0 & -1 & -1 & 1 & 52.42 & 54.54 & 4.06 & 57.37 & 9.45 \\
\hline 0 & 0 & -1 & 1 & 57.40 & 56.24 & 2.02 & 54.27 & 5.46 \\
\hline 1 & 0 & -1 & 1 & 58.31 & 60.21 & 3.26 & 54.13 & 7.17 \\
\hline
\end{tabular}

It should be remembered that the increase of the relative contact bearing area (2) secures a higher reliability of the part contact. Fig. 3 illustrates the predicting response surfaces at two stages of grinding: $\mathrm{a}-t=0.02 \mathrm{~mm}, z=0.3 \mathrm{~mm}-$ rough; $\mathrm{b}-t=0.005 \mathrm{~mm}, z=0.1 \mathrm{~mm}-$ finishing. In Fig. 3, a presented response surface has a minimum at $s_{l}=6 \mathrm{~m} / \mathrm{min}$ with a decrease of $\hat{t}_{f M}$ in the direction of increasing the longitudinal feed. At the same time, the global maximums were marked at two points: $\hat{t}_{f M}=44.31 \%$ at $s_{l}=5 \mathrm{~m} / \mathrm{min}$ and $s_{\mathrm{cr}}=2$ 
$\mathrm{mm} /$ double stroke and $\hat{t}_{f M}=42.34 \%$ at $s_{l}=5 \mathrm{~m} / \mathrm{min}$ and $s_{c r}$ $=10 \mathrm{~mm} /$ double stroke. Unfortunately, the actual contact area decreases with increasing the longitudinal feed, especially while grinding with low cross feed. It reduces the process performance.

It was found that at the finishing stage of grinding the VT22 parts, the maximums of the relative contact bearing area were shifted to the zones with variable feeds: $\hat{t}_{f M}=61.67 \%-$ at $s_{l}=5 \mathrm{~m} / \mathrm{min}, s_{c r}=10 \mathrm{~mm} /$ double stroke; $\hat{t}_{f M}=62,14 \%-$ at $s_{l}=18 \mathrm{~m} / \mathrm{min}, s_{c r}=4 \mathrm{~mm} /$ double stroke. Two presented cutting modes are equivalent by process productivity, but the second mode allows to reduce the process heat intensity and is preferable. Grinding with the greatest cross feed $s_{\mathrm{c}}=10$ $\mathrm{mm}$ /double stroke is the most negative condition for forming the relative contact bearing area of ground surfaces. Its value is bluntly reduced to $\hat{t}_{f M}=34 \%$ at $s_{l}=18 \mathrm{~m} / \mathrm{min}$.
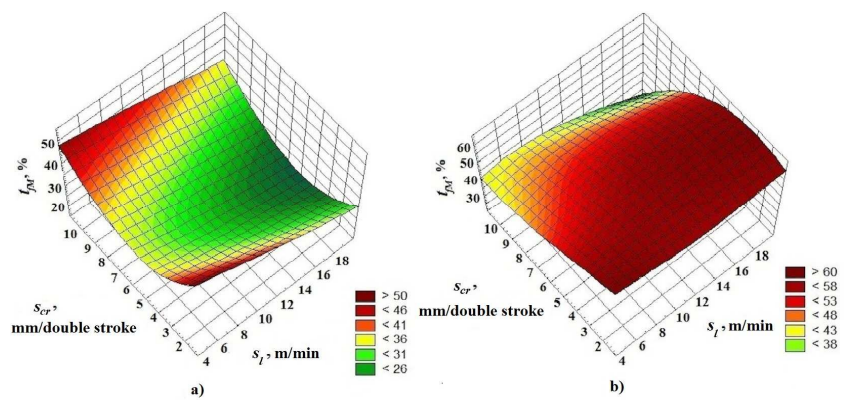

Fig. 3. Influence of longitudinal and cross feeds on the relative contact bearing area of workpiece surface at: $\mathrm{a}-\mathrm{t}=0.02 \mathrm{~mm}, \mathrm{z}=0.3 \mathrm{~mm}, \mathrm{~b}-\mathrm{t}=0.005$ $\mathrm{mm}, \mathrm{z}=0.1 \mathrm{~mm}$

To evaluate the influence of the cutting depth and the operating allowance on the relative contact bearing area of ground surfaces, the analysis of the predicting responses is carried out at the constant technological parameters: $s_{l}=18$ $\mathrm{m} / \mathrm{min}, s_{c}=10 \mathrm{~mm} /$ double stroke (Fig. 4,a) - for rough
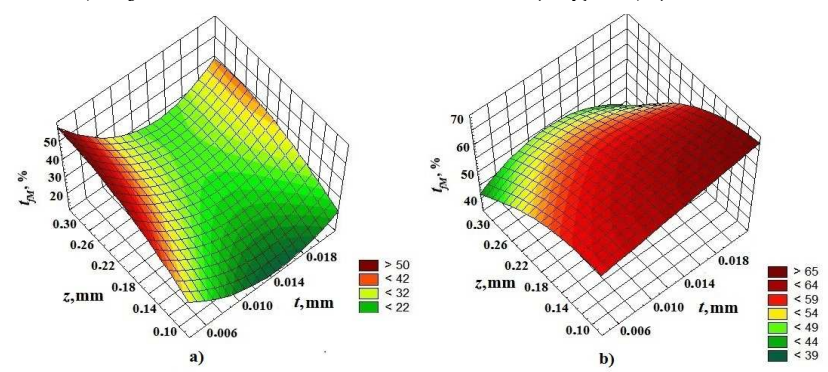

Fig. 4.Influence of the cutting depth and the operating allowance on the relative contact bearing area of ground surfaces at: $\mathrm{a}-s_{l}=18 \mathrm{~m} / \mathrm{min}, s_{c r}=10 \mathrm{~mm} /$ double stroke; b $-s_{l}=5 \mathrm{~m} / \mathrm{min}$, $s_{c r}=2 \mathrm{~mm} /$ double stroke

grinding; $s_{l}=5 \mathrm{~m} / \mathrm{min}, s_{c}=2 \mathrm{~mm} /$ double stroke (Fig. 4,b) - for finishing grinding.

It is seen from Fig. 4 that the shapes of the surface responses retained the forms of presented earlier responses in
Fig. 3. The surface concavity is along the axis $z$ for rough grinding (Fig. 4,a). Its convexity is along the axis $z$, especially in the zone $z \geq 0.16 \mathrm{~mm}$, for finishing grinding. The most favorable conditions for forming the relative contact bearing area with the greatest $\hat{t}_{f M}=53.175 \%$ was marked at the point ( $t=0.006 \mathrm{~mm}$ and $z=0.3 \mathrm{~mm}$ ). The second conditional maximum $\hat{t}_{f M}=40 \%$ was predicted along the axis $t$ to 0.015 $\mathrm{mm}$. It is lower than the absolutely extreme, but it provides increasing the grinding productivity to 2.5 times. Fig. 4,b illustrates the influence of the technological parameters of finishing grinding on the relative contact bearing area. The greatest its values were marked at the point $(t=0.02 \mathrm{~mm}, z=$ $0.1 \mathrm{~mm}$ ) with $\hat{t}_{f M}=65.96 \%$. Its value is sharply reduced to $\hat{t}_{f M}=40 \%$, if the cutting depth was not changed and the operating allowance was increased.

\section{CONCLUSIONS}

The high efficiency of application of the technique of measuring the relative contact bearing area of ground surfaces using digital technologies has been confirmed.

It is established that the ANN model provides a higher predicting accuracy in comparison with the MANOVA models.

It has been revealed that the decrease of technological parameters is not always accompanied by the increase of the predicted value of the relative contact bearing area.

It is established that with the aim of increasing the process productivity and the relative contact bearing area of ground surfaces, the parts from titanium alloy VT22 are recommended to grind by the following modes: for rough stage $-s_{l}=5-12$ $\mathrm{m} / \mathrm{min}, s_{c r}=9-10 \mathrm{~mm} /$ double stroke, $t=0.02 \mathrm{~mm}, z=0.3 \mathrm{~mm}$; and for finishing stage $-s_{l}=18 \mathrm{~m} / \mathrm{min}, s_{c r}=4 \mathrm{~mm} /$ double stroke, $t=0.006 \mathrm{~mm}, z=0.1 \mathrm{~mm}$.

\section{References}

[1] A.G Suslov, Quality of the surface layer of machine parts, Mechanical engineering, Moscow, 2000.

[2] V.M. Popov, Heat exchange in the contact zone of detachable and fixed connections, Energy, Moscow, 1971.

[3] I.V. Klagelsky and N.B. Demkin, "Contact area of rough surfaces", Wear, Vol. 3(3), pp. 170-187, 1960.

[4] N.B. Demkin and E.V. Ryzhov, Surface quality and contact of machine parts, Mechanical Engineering, Moscow, 1981.

[5] V.M. Gryazev, "Selection of the method for determining the actual contact area of surfaces of interacting parts", Proceedings of TULGU, Technical science, Vol. 10, pp. 26-32, 2013.

[6] F.Ya. Zagavura, L.A. Kadenatsii, L.I. Lysenko, and B.M. Uvarov, "New methods for determining the actual contact area of solid bodies", Measurement Techniques, Vol. 13(12), pp. 1847-1849, 1970.

[7] A.M. Firsov and V.N. Belyaev, Patent RU 2301967 C1, 2006.

[8] Ya.I. Soler, D.S. Mai, and D.Y. Kazimirov, "Technological opportunities for increasing a bearing surface of flat parts made from VT22 alloy during pendulum grinding", ARPN Journal of Engineering and Applied Sciences, Vol. 11(17), pp. 10190-10200, 2016. 
[9] V.A. Nosenko and S.V. Nosenko, Technology of grinding metals, Monograph, Stary Oskol: TNT, 2013.

[10] D. Fu, W. Ding, S. Yang, Q. Miao, and Y. Fu, "Formation mechanism and geometry characteristics of exit-direction burrs generated in surface grinding of Ti-6Al-4V titanium alloy", The International Journal of Advanced Manufacturing Technology, Vol. 89(5-8), pp. 2299-2313, 2017.

[11] G. Guo, Z. Liu, Q. An, and M. Chen, "Experimental investigation on conventional grinding of Ti-6Al-4V using $\mathrm{SiC}$ abrasive", The International Journal of Advanced Manufacturing Technology, Vol. 57(1-4), pp. 135-142, 2011.

[12] W. Ryszard, "The grinding of titanium alloys", Archives of Mechanical. Technology and Automation, Vol. 33(4), pp. 49-60, 2013.

[13] Z.I. Kremen, D.A. Popovskii, and V.G. Yur'ev, "Grinding of titanium alloys by elbor and diamond wheels", Russian Engineering Research, Vol. 33(8), pp. 457-459, 2013.

[14] S.V. Nosenko, V.A. Nosenko, and A.A. Bairamov, "Factors affecting the surface roughness in the deep grinding of titanium alloys", Russian Engineering Research, Vol. 35(7), pp. 549-553, 2015.

[15] X. Xu, Y. Yu, and H. Huang, "Mechanisms of abrasive wear in the grinding of titanium (TC4) and nickel (K417) alloys", Wear, Vol.255, pp. 1421-1426, 2003.
[16] C. Mao, Z.X. Zhou, Y.H. Ren, and B. Zhang, "Analysis and FEM simulation of temperature field in wet surface grinding", Mater Manuf Process, Vol. 25, pp. 399-406, 2010.

[17] M. Chandrasekaran and D. Devarasiddappa, "Artificial neural network modeling for surface roughness prediction in cylindrical grinding of $\mathrm{Al} \square \mathrm{SiCp}$ metal matrix composites and ANOVA analysis", Advances in production engineering and management, Vol. 9(2), pp. 59-70, 2014.

[18] Y.M. Ali and L.C. Zhang, "Surface roughness prediction of ground components using a fuzzy logic approach", Journal of materials processing technology, Vol. 89, pp. 561-568, 1999.

[19] D.Anderson, A. Warkentin, and R. Bauer, "Experimental validation of numerical thermal models for dry grinding", J Mater Process Technol, Vol. 204, pp. 269-278, 2008.

[20] Ya.I. Soler, V.L. Nguyen, and D.Yu. Kazimirov, "Modeling of Burns When Grinding Hardened 30KhGSA Steel Parts", Proceedings of higher educational institutions. Mechanical engineering, Vol. 4(673), pp. 71-81, 2016.

[21] H.M. Raymond, C.M. Douglas and M.A. Christine, Response surface methodology: process and product optimization using designed experiments, John Wiley \& Sons, New Jersey, 2009. 